\title{
Oxidative Modification of Neurofilament-L Induced by Endogenous Neurotoxin, Salsolinol
}

\author{
Jung Hoon Kang \\ Department of Genetic Engineering, Cheongju University, Cheongju 360-764, Korea. E-mail: jhkang@cju.ac.kr \\ Received April 27, 2011, Accepted July 31, 2011
}

\begin{abstract}
The endogenous neurotoxin, 1-methyl-6,7-dihydroxy-1,2,3,4-tetrahydroisoquinoline (salsolinol), has been considered a potential causative factor for the pathogenesis of Parkinson's disease (PD). In this study, we examined oxidative modification of neurofilament-L (NF-L) induced by salsolinol. When disassembled NF-L was incubated with salsolinol, the aggregation of protein was increased with the concentration of sasolinol. The formation of carbonyl compound was obtained in salsolinol-mediated NF-L aggregates. This process was protected by free radical scavengers, such as $N$-acetyl-L-cysteine and glutathione. These results suggest that the aggregation of NF-L is mediated by salsolinol via the generation of free radicals. We also investigated the effects of copper ion on salsolinol-mediated NF-L modification. In the presence of copper ions, salsolinol enhanced the modification of NF-L. We suggest that salsolinol might be related to abnormal aggregation of NF-L which may be involved in the pathogenesis of neurodegenerative diseases and related disorders.
\end{abstract}

Key Words : Salsolinol, Neurofilament, Free radical, Parkinson's disease

\section{Introduction}

Salsolinol (1-methyl-6,7-dihydroxy-1,2,3,4-tetrahydroisoquinoline) (Fig. 1) is an endogenous catechol-derived neurotoxin supposedly related to the development of Parkinson's disease (PD). Previous studies have shown that salsolinol is toxic to dopaminergic neurons under both in vitro and in vivo conditions. It has also been reported that salsolinol in conjugation with transition metal ions undergoes redox cycling to generate reactive oxygen species (ROS), most notably hydroxyl radicals which induce DNA strand scission and cell death. ${ }^{1}$ Recent report has been revealed that salsolinol induced cell death by causing oxidative stress in dopaminergic SH-SY5Y cells, and prevented by metallothionein. ${ }^{2}$

Neurofilament proteins have been implicated in the pathogenesis of several neurodegenerative disorders. Recent progress in PD research indicates that PD might be caused by protein aggregation due to aberrant protein folding or disturbed protein degradation. ${ }^{3}$ Lewy bodies (LBs) are cytoplasmic inclusions that are present consistently and with greatest frequency in neurons of the substantia nigra and locus ceruleus of patients with PD. ${ }^{4}$ Neurofilament proteins have been identified immunohistochemically as the major protein components of LB filament. ${ }^{5}$ Neurofilaments are<smiles>CC1NCCc2cc(O)c(O)cc21</smiles>

SALSOLINOL

Figure 1. The structure of salsolinol. composed of three subunits, identified as light (NF-L), medium (NF-M), and heavy (NF-H), which assemble in a 6:2:1 ratio to form long macromolecular filaments. ${ }^{6,7}$ All three subunits have been identified in LB. ${ }^{8}$

Abnormal accumulation of neurofilaments in neurons is associated with other neurodegenerative diseases, such as Alzheimer disease (AD) ${ }^{9}$ and amyotrophic lateral sclerosis (ALS). ${ }^{10}$ It has been reported that the overexpression of mouse NF-L led to the severe loss of neurons in the parietal cortex and ventrobasal thalamus with age. ${ }^{11}$ Other studies showed that transgenic mice overexpressing 4-fold mouse NF-L cause neuron degeneration and neuron loss, which resembles the pathology of ALS. ${ }^{12}$ More recently, mass spectrometry revealed that the neuronal staining by glial fibrillary protein antibody was caused by a cross-reaction with NF-L. ${ }^{13}$ This study implied that NF-L could accumulate in some tangle-like structures in Alzheimer brains. However, the precise biochemical and molecular mechanism underlying the salsolinol-mediated modification of neurofilament proteins is not reported. In the present study, we have investigated the oxidative modification of NF-L induced by salsolinol. Our results revealed that salsolinol led to the aggregation of NF-L through the generation of ROS. We found that copper ions enhanced salsolinol-mediated NF-L aggregation.

\section{Materials and Methods}

Materials. Salsolinol, sodium azide, $N$-acetyl-L-cysteine, glutathione, 2,4-dinitrophenyl hydrazine, 5,5-dimethyl-1pyrroline $N$-oxide (DMPO), and trichloroacetic acid (TCA) were purchased from Sigma (St. Louis, MO, USA). Chelex 100 resin (sodium form) was obtained from Bio-Rad (Hercules, CA, USA). All solutions were treated with Chelex 100 
resin to remove traces of transition metal ions.

Expression and Purification of Neurofilament-L. A full-length cDNA clone of mouse NF-L in a pET-3d vector, a generous gift from Dr. Beckman (University of Alabama) was transformed into E. coli (BL21). Protein expression was performed as previously described. ${ }^{14}$ Bacteria were grown in Luria broth supplemented with $1 \mathrm{mM}$ isopropyl $\beta$-D-thiogalactopyranoside beginning at an OD $600 \mathrm{~nm}$ reading of 0.8 . Incubation was at $37^{\circ} \mathrm{C}$ for $3 \mathrm{~h}$. Bacteria were harvested by centrifugation $\left(4,000 \times \mathrm{g}\right.$ for $10 \mathrm{~min}$ at $\left.4{ }^{\circ} \mathrm{C}\right)$, and resuspended in standard buffer $(50 \mathrm{mM}$ MES, $170 \mathrm{mM}$ $\mathrm{NaCl}, 1 \mathrm{mM}$ DDT, pH 6.25). The cells were lysed with a French press at a pressure of 20,000 pounds per square inch and centrifuged at $8,000 \times \mathrm{g}$ for $15 \mathrm{~min}$ at $4{ }^{\circ} \mathrm{C}$. The supernatant was incubated for $3 \mathrm{~h}$ at $37^{\circ} \mathrm{C}$ and then was centrifuged at $100,000 \times \mathrm{g}$ for $20 \mathrm{~min}$ at $25^{\circ} \mathrm{C}$. The pellets containing the aggregated NF-L proteins were washed twice with standard buffer before they were dissolved in urea buffer (25 mM Na-phosphate, $\mathrm{pH} 7.5,6 \mathrm{M}$ urea, $1 \mathrm{mM}$ EGTA and $1 \mathrm{mM}$ DDT). The sample was loaded onto a DEAE-sepharose column and the column was washed with urea buffer. The column was eluted with a linear 25-500 mM phosphate gradient in urea buffer and $1 \mathrm{~mL}$ NF-L eluted between 300 and $360 \mathrm{mM}$ phosphate. These fractions were pooled and either used directly or stored at $-70{ }^{\circ} \mathrm{C}$ for later experiments. Protein concentration was determined by the BCA method. ${ }^{15}$

Oxidation of Protein. Oxidative modification of NF-L $(0.4 \mathrm{mg} / \mathrm{mL})$ was carried out by incubation of the protein with salsolinol in $10 \mathrm{mM}$ potassium phosphate buffer $(\mathrm{pH}$ $7.5)$ at $37^{\circ} \mathrm{C}$. After incubation of the reaction mixtures $(0.1$ $\mathrm{mL}$ ), the mixtures were then placed into Ultrafree-MC filter and centrifuged at $10,000 \times \mathrm{g}$ for $1 \mathrm{~h}$ and then washed with Chelex 100 treated water and centrifuged for $1 \mathrm{~h}$ at same speed. This was repeated four times. The filtrate was dried by freeze drier and dissolved with phosphate buffer.

Analysis of Modified Protein. After treatment with various concentrations of salsolinol for $6 \mathrm{~h}$, samples of the reaction mixtures were diluted with a concentrated sample buffer $(0.25 \mathrm{mM}$ Tris, $40 \%$ glycerol, $0.01 \%$ bromophenol blue). An aliquot of each sample was subjected to SDSPAGE as described by Laemmli ${ }^{16}$ using a $12 \%$ acrylamide slab gel. The gels were stained with $0.15 \%$ Coomassie Brilliant Blue R-250.

Detection of Carbonyl Moiety in the Protein. The carbonyl contents of the proteins were determined via spectrophotometric assays, as described elsewhere. ${ }^{17}$ Both native and oxidized proteins were incubated with $10 \mathrm{mM}$ 2,4-DNPH in $2.5 \mathrm{M} \mathrm{HCl}$ for $1 \mathrm{~h}$ at room temperature. After incubation, 20\% TCA was added to the sample and the tubes were left in an ice bucket for $10 \mathrm{~min}$ and then centrifuged for 5 min with a tabletop centrifuge to collect the protein precipitates, after which the supernatants were discarded. Another wash was performed using 10\% TCA, and the protein pellets were mechanically broken using a pipette tip. Finally, the pellets were washed 3 times with ethanol-ethyl acetate $(1: 1)(\mathrm{v} / \mathrm{v})$ to remove any free DNPH. The final precipitates were dissolved in $2 \mathrm{~mL}$ of $6 \mathrm{M}$ guanidine hydrochloride solution and left for $10 \mathrm{~min}$ at $37{ }^{\circ} \mathrm{C}$ with general vortex mixing. Carbonyl contents were calculated from the absorbance $(370 \mathrm{~nm})$ with an absorption coefficient $\varepsilon$ of $22,000 \mathrm{M}^{-1} \mathrm{~cm}^{-1}$.

Effect of Free Radical Scavengers and Spin Trap Agent on Salsolinol-mediated NF-L Modification. NF-L $(0.4 \mathrm{mg} / \mathrm{mL})$ was incubated with $1 \mathrm{mM}$ salsolinol at $37{ }^{\circ} \mathrm{C}$ for $6 \mathrm{~h}$ in the presence of free radical scavengers and spin trap agent for $6 \mathrm{~h} .100 \mathrm{mM}$ azide, $100 \mathrm{mM}$ mannitol, $25 \mathrm{mM}$ $\mathrm{N}$-acetyl-L-cysteine and $25 \mathrm{mM}$ glutathione were used as the free radical scavengers. $100 \mathrm{mM}$ DMPO was used as a spin trap agent. An aliquot of each sample was subjected to SDSPAGE as described by Laemmli ${ }^{16}$ using a $12 \%$ acrylamide slab gel.

Effect of Free Radical Scavengers and Spin Trap Agent on on the Formation of Carbonyl Compounds After the Incubation of NF-L with Salsolinol. NF-L (1 $\mathrm{mg} / \mathrm{mL}$ ) was incubated with $1 \mathrm{mM}$ salsolinol $10 \mathrm{mM}$ potassium phosphate buffer ( $\mathrm{pH}$ 7.4) in the presence of 25 $\mathrm{mM} N$-acetyl-L-cysteine or $25 \mathrm{mM}$ glutathione or $100 \mathrm{mM}$ DMPO at $37^{\circ} \mathrm{C}$ for $6 \mathrm{~h}$. Reaction mixtures reacted with 2,4dinitrophenyl hydrazine and then the derivatives were measured by spectrophotometry.

Statistical Analysis. Values are expressed as the means \pm S.D of three to five separate experiments. The statistical differences between the means were determined by the Student $t$-test.

\section{Results and Discussion}

To determine whether the modification of NF-L was induced by salsolinol, the reaction mixtures containing NF-L and salsolinol were subjected to SDS-PAGE analysis. As shown in Figure 2, there was a salsolinol concentrationdependent increase in the formation of protein aggregates. When NF-L was incubated with $1 \mathrm{mM}$ salsolinol, most of the protein was at the top of the gel. Neurofilaments proteins specifically expressed in neuron and axons, have been implicated in a range of neurodegenerative disorders. ${ }^{18-20}$

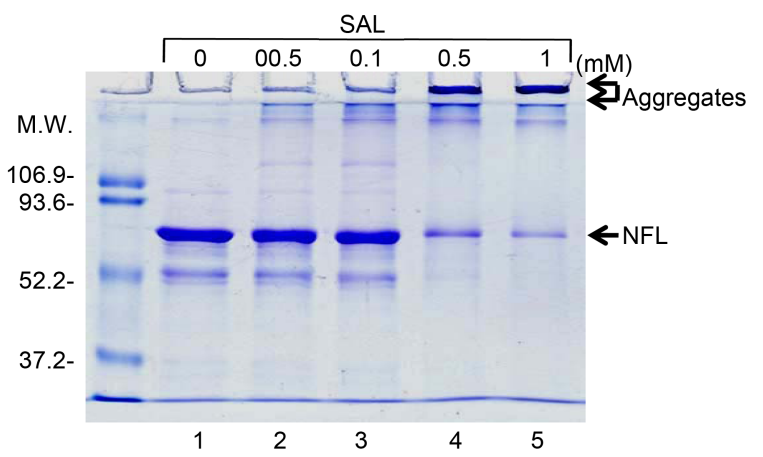

Figure 2. Aggregation of NF-L by salsolinol. NF-L $(0.4 \mathrm{mg} / \mathrm{mL})$ was incubated with various concentrations of salsolinol. Lane 1 , NF-L control; lane 2, NF-L + $0.05 \mathrm{mM}$ salsolinol; lane 3, NF-L + $0.1 \mathrm{mM}$ salsolinol; lane 4, NF-L + $0.5 \mathrm{mM}$ salsolinol; lane 5, NF-L $+1 \mathrm{mM}$ salsolinol. The positions of molecular weight markers $(\mathrm{kDa})$ are indicated on the left. 


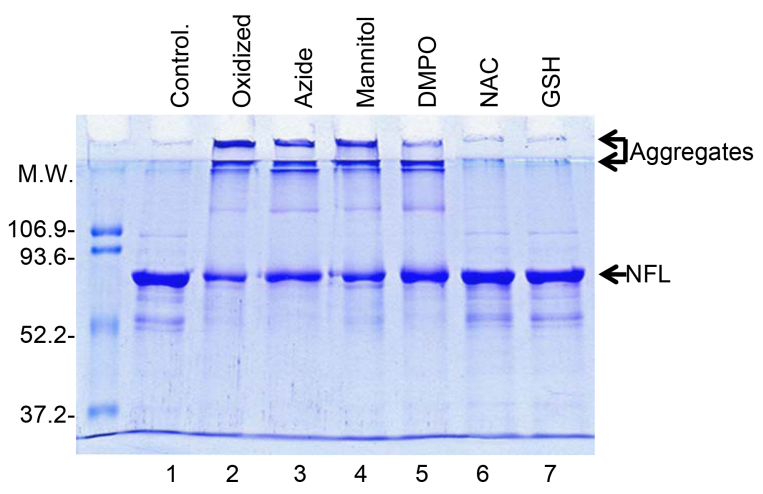

Figure 3. Effect of free radical scavengers and spin trap agent on salsolinol-mediated NF-L modification. NF-L $(0.4 \mathrm{mg} / \mathrm{mL})$ was incubated with $1 \mathrm{mM}$ salsolinol at $37^{\circ} \mathrm{C}$ for $6 \mathrm{~h}$ in the presence of radical scavengers and spin trap agent. Lane 1, NF-L control; lane 2, NF-L + salsolinol; lane 3, lane $2+100 \mathrm{mM}$ azide; lane 4, lane 2 + $100 \mathrm{mM}$ mannitol; lane 5, lane 2 + $100 \mathrm{mM}$ DMPO; lane 6, lane $2+25 \mathrm{mM} \mathrm{N}$-acetyl-L-cysteine (NAC); lane 7, lane $2+25 \mathrm{mM}$ glutathione $(\mathrm{GSH})$. The positions of molecular weight markers $(\mathrm{kDa})$ are indicated on the left.

The common feature is the slow accumulation of neurofilament aggregates in neuronal cells accompanied by cell death. Since abnormal accumulation of neurofilaments was closely associated with neurodegenerative disorders, the aggregation of NF-L might have pathological significance.

The participation of free radicals in the modification of NF-L by salsolinol was studied by examining the inhibition of free radical scavengers and spin trap agent during the reaction of NF-L with slasolinol. The modification of NF-L was slightly suppressed in the presence of azide, mannitol, and DMPO, whereas the protein modification was significantly inhibited by $\mathrm{N}$-acetyl-L-cysteine and glutathione (Fig. 3). These results suggest that free radicals may participate in salsolinol-mediated NF-L modification. Our data provide indirect support for the recent hypothesis of an involvement of NF-L in several neurological disorders. ${ }^{21}$

With the discovery that protein oxidation results in the conversion of certain amino acid residues to carbonyl derivatives, ${ }^{22}$ the presence of protein carbonyls has been employed fairly extensively as a measure of oxidative damage. ${ }^{23}$ The method utilized for the detection of carbonylcontaining proteins involves derivatization with $2,4-\mathrm{DNPH}$ followed by spectrophotometric analysis. ${ }^{16}$ The result showed that the formation of carbonyl was increased with the concentration of salsolinol (Fig. 4). Because free radicals led to the formation of carbonyl moiety in the protein, we investigated the effects of free radical scavengers and spin trap agent on protein carbonyl compound formation. $\mathrm{N}$ Acetyl-L-cysteine, glutathione and DMPO inhibited the formation of carbonyl compounds in salsolinol-treated NF-L (Fig. 5). Protein carbonyls are generally detected at increased levels in both $\mathrm{PD}^{24}$ and $\mathrm{AD} .{ }^{25}$ Oxidative modification of proteins by either the $\alpha$-amidation pathway or oxidation of glutamyl side chains leads to formation of a peptide in which the N-terminal amino acid is blocked by an $\alpha$-ketoacyl derivative. However, it has been shown that direct oxidation

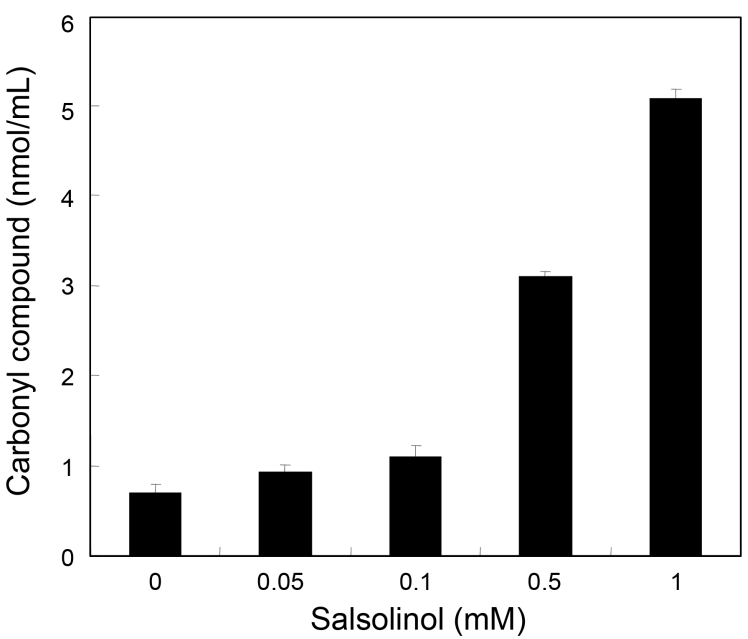

Figure 4. Determination of carbonyl compounds after the incubation of NF-L with salsolinol. NF-L $(1 \mathrm{mg} / \mathrm{mL})$ was incubated with various concentration of salsolinol in $10 \mathrm{mM}$ potassium phosphate buffer ( $\mathrm{pH} \mathrm{7.4)}$ at $37^{\circ} \mathrm{C}$ for $6 \mathrm{~h}$. Reaction mixtures reacted with 2,4dinitrophenyl hydrazine and then the derivatives were measured by spectrophotometry.

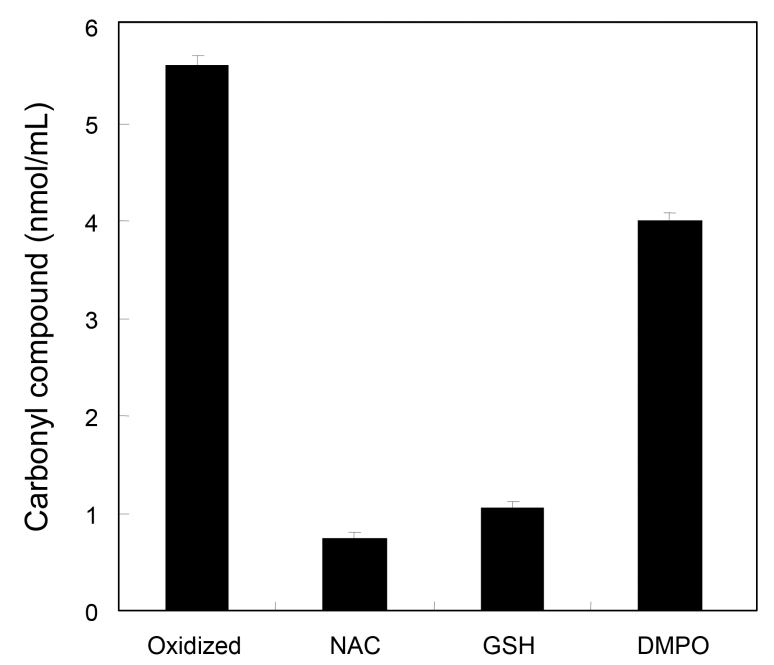

Figure 5. Effect of free radical scavengers and spin trap agent on the formation of carbonyl compounds after the incubation of NF-L with salsolinol. NF-L $(1 \mathrm{mg} / \mathrm{mL})$ was incubated with $1 \mathrm{mM}$ salsolinol in $10 \mathrm{mM}$ potassium phosphate buffer $(\mathrm{pH}$ 7.4) in the presence of $25 \mathrm{mM} N$-acetyl-L-cysteine (NAC) or $25 \mathrm{mM}$ glutathione (GSH) or $100 \mathrm{mM} \mathrm{DMPO}$ at $37^{\circ} \mathrm{C}$ for $6 \mathrm{~h}$. Reaction mixtures reacted with 2,4-dinitrophenyl hydrazine and then the derivatives were measured by spectrophotometry.

of lysine, arginine, proline, and threonine residues may also yield carbonyl derivatives. ${ }^{26}$ The presence of carbonyl groups in proteins has therefore been used as a marker of ROSmediated protein oxidation in neurodegenerative disorders.

Trace metal such as iron and copper, which are variously present in biological systems, were shown to generate $\cdot \mathrm{OH}$ through Fenton reaction and then led to damages of macromolecules. ${ }^{27-30}$ The cleavage of the metalloproteins by oxidative damage may lead to increases in the levels of metal ions in some biological cells. ${ }^{31}$ It has been reported that copper concentration was significantly increased in the 


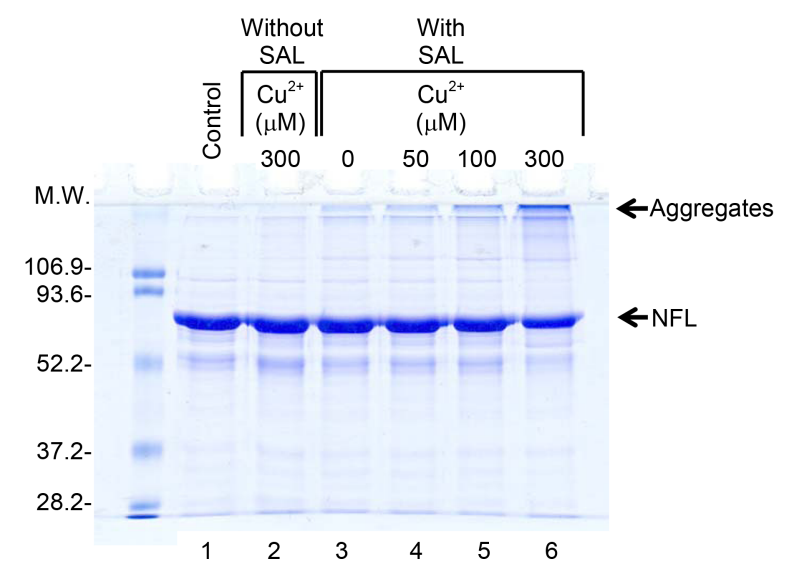

Figure 6. Effect of copper ion on salsolinol-mediated NF-L modification. NF-L $(0.4 \mathrm{mg} / \mathrm{mL})$ was incubated with $0.05 \mathrm{mM}$ salsolinol (SAL) at $37^{\circ} \mathrm{C}$ for $6 \mathrm{~h}$. Lane 1, NF-L control; lane 2, 300 $\mu \mathrm{M} \mathrm{CuSO}_{4}$ without SAL; lane 3, $\mathrm{SAL}_{\text {without }} \mathrm{CuSO}_{4}$; lane 4, 50 $\mu \mathrm{M} \mathrm{CuSO}_{4}+\mathrm{SAL}$; lane 5, $100 \mu \mathrm{M} \mathrm{CuSO}_{4}+\mathrm{SAL}$; lane 6, $300 \mu \mathrm{M}$ $\mathrm{CuSO}_{4}+\mathrm{SAL}$

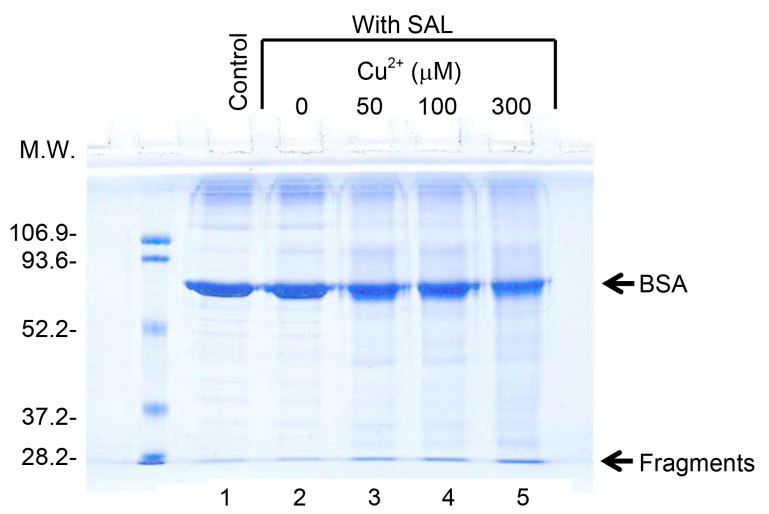

Figure 7. Effect of copper ion on salsolinol-mediated bovine serum albumin (BSA) modification. BSA $(0.5 \mathrm{mg} / \mathrm{mL})$ was incubated with $0.05 \mathrm{mM}$ salsolinol (SAL) at $37^{\circ} \mathrm{C}$ for $6 \mathrm{~h}$. Lane 1 , BSA control; lane 2, SAL without $\mathrm{CuSO}_{4}$; lane 3, $50 \mu \mathrm{M} \mathrm{CuSO}_{4}+\mathrm{SAL}$; lane 4, $100 \mu \mathrm{M} \mathrm{CuSO}_{4}+\mathrm{SAL}$; lane 5, $300 \mu \mathrm{M} \mathrm{CuSO}_{4}+\mathrm{SAL}$.

cerebrospinal-fluid of PD patients ${ }^{32}$ and that in the cerebrospinal-fluid copper concentration was increased 2.2-fold in AD patients. ${ }^{33}$ These reports suggested that copper-catalyzed oxidative reaction might contribute to the pathogenesis of neurodegenerative disorders. In the present study, we investigated the effects of copper on salsolinol-mediated NF-L modification. When NF-L was incubated with copper ion alone, the protein remained (Fig. 6, lane 2). However, the protein was aggregated after the incubation of salsolinol and copper ion (Fig. 6, lanes 4-6). These results suggested that copper ions might be involved in the modification of NF-L induced by salsolinol. We investigated whether this effect specific to NF-L. When bovine serum albumin (BSA) was incubated with salsolinol and copper ion, the modification of protein increased in a copper ion concentration-dependent manner. However, unlike NF-L, BSA showed a fragment patterns (Fig. 7). It is therefore evident that the effect of copper ion elicits a different pattern of protein oxidation.

In summary, the modification of NF-L was induced by salsolinol, involving free radical generation. The copper ions can lead to protein oxidation in salsolinol-mediated neurodegeneration. Therefore, the salsolinol-mediated NF-L modification might be associated with the pathogenesis of $\mathrm{PD}$ and related disorders.

\section{References}

1. Surh, Y. J.; Jung, Y. J.; Jung, J. H.; Lee, J. S.; Yoon, H. R. J. Toxicol. Environ. Health Part A 2002, 65, 473-488.

2. Wanpen, S.; Govitrapong, P.; Shrali, S.; Sangchot, P.; Ebadi, M. Brain Res. 2004, 1005, 67-76.

3. Riess, O.; Kuhn, W.; Kruger, R. J. Neurol. 2000, 247 (Suppl. 2) II69-II74.

4. Forno, L. S. Adv. Neurol. 1987, 45, 35-43.

5. Pollanen, M. S.; Dickson, D. W.; Bergeron, C. J. Neuropathol. Exp. Neurol. 1993, 52, 183-191.

6. Nixon, R. A.; Lewis, S. E. J. Biol. Chem. 1986, 261, 16298-16301.

7. Nixon, R. A.; Shea, T. B. Cell Motil. Cytoskeleton 1992, 22, 81-91.

8. Hill, W. D.; Lee, V. M.; Hurtig, H. I.; Murray, J. M.; Trojanowski, J. Q. J. Comp. Neurol. 1991, 309, 150-160.

9. Shepherd, C. E.; McCann, H.; Thiel, E.; Halliday, G. M. Neurobiol. Dis. 2002, 9, 249-257.

10. Collard, J. F.; Cote, F.; Julien, J. P. Nature 1995, 375, 61-64.

11. Ma, D.; Descarries, L.; Micheva, K. D.; Lepage, Y.; Julien, J. P.; Doucet, G. J. Comp. Neurol. 1999, 406, 433-448.

12. Xu, Z.; Cork, L. C.; Griffin, J. W.; Cleveland, D. W. Cell 1993, 73, 23-33.

13. Middeldorp, J.; van den Berge, S. A.; Aronica, E.; Speijer, D.; Hol, E. M. PLoS ONE. 2009, 4, 7663-7669.

14. Kang, J. H. Bull. Korean Chem. Soc. 2007, 28, 77-80.

15. Smith, M. A.; Rudnicka-Nawrot, M.; Richey, P. L.; Praprotnik, D.; Mulvihill, P.; Miller, C. A.; Sayre, L. M.; Perry, G. J. Neurochem. 1995, 64, 2660-2666.

16. Laemmli, U. K. Nature 1970, 227, 680-685.

17. Reznick, A. Z.; Packer, L. Methods Enzymol. 1994, 233, 357-363.

18. Collard, J. F.; Cote, F.; Julien, J. P. Nature 1995, 375, 61-64.

19. Shepherd, C. E.; McCann, H.; Thiel, E.; Halliday, G. M. Neurobiol. Dis. 2002, 9, 249-257.

20. Rahner, N.; Holzmann, C.; Krüger, R.; Schöls, L.; Berger, K.; Riess, O. Brain Res. 2002, 951, 82-86.

21. Teunissen, C. E.; Iacobaeus, E.; Khademi, M.; Brundin, L.; Norgren, N.; Koel-Simmelink, M. J.; Schepens, M.; Bouwman, F.; Twaalfhoven, H. A.; Blom, H. J.; Jakobs, C.; Dijkstra, C. D. Neurology 2009, $72,1322-1329$.

22. Levine, R. L.; Williams, J. A.; Stadtman, E. R.; Shacter, E.; Methods Enzymol. 1994, 233, 346-357.

23. Murray, J.; Oquendo, C. E.; Willis, J. H.; Marusich, M. F.; Capaldi, R. A. Adv. Drug Deliv. Rev. 2008, 60, 1497-1503.

24. Soto-Otero, R.; Sanmartin-Suarez, C.; Sanchez-Iglesias, S.; HermidaAmeijeiras, A.; Sanchez-Sellero, I.; Mendez-Alvarez, E. J. Biochem. Mol. Toxicol. 2006, 20, 209-220.

25. Perluigi, M.; Joshi, G.; Sultana, R.; Calabrese, V.; De Marco, C.; Coccia, R. D.; Butterfield, D. A. Neuroscience 2006, 138, 1161-1170.

26. Berlett, B. S.; Stadtman, E. R. J. Biol. Chem. 1997, 272, 20313-20316.

27. Halliwell, B.; Gutteridge, J. M. FEBS Lett. 1992, 307, 108-112.

28. Imlay, J. A.; Chin, S. M.; Linn, S. Science 1988, 240, 640-642.

29. Sagripanti, J. L.; Kraemer, K. H. J. Biol. Chem. 1989, 264, 17291734.

30. Sagripanti, J. L.; Swicord, M. L.; Davis, C. C. Radiat. Res. 1987, 110, 219-231.

31. O’Connell, M. J.; Peters, T. J. Chem. Phys. Lipids 1987, 45, 241249.

32. Pall, H. S.; Williams, A. C.; Blake, D. R.; Lunec, J.; Gutteridge, J. M.; Hall, M.; Taylor, A. Lancet 1987, 2, 238-241.

33. Multhaup, G.; Schlicksupp, A.; Hesse, L.; Behler, D.; Ruppert, T.; Masters, C. L.; Beyreuther, K. Science 1996, 271, 1406-1409. 